\title{
Baseline malaria prevalence at the targeted pre-elimination districts in Ethiopia
}

Desalegn Nega ${ }^{1 * \dagger}$, Adugna Abera ${ }^{1 \dagger}$, Bokretsion Gidey ${ }^{1}$, Sindew Mekasha ${ }^{1}$, Abnet Abebe ${ }^{1}$, Dereje Dillu ${ }^{2}$, Degu Mehari ${ }^{2}$, Gudissa Assefa², Samuel Hailu², Mebrahatom Haile², Kebede Etana ${ }^{2}$, Hiwot Solomon², Gezahagn Tesfaye ${ }^{2}$, Daniel Nigatu ${ }^{3}$, Zelalem Destaw ${ }^{1}$, Berhane Tesfaye $^{4}$, Belendia Serda ${ }^{4}$, Asnakew Yeshiwondim ${ }^{4}$ Assefaw Getachew ${ }^{4}$, Hiwot Teka ${ }^{5}$, Honelegn Nahusenay ${ }^{6}$, Semira Abdelmenan ${ }^{6}$, Hailemariam Reda 7 , Worku Bekele ${ }^{8}$, Ayele Zewdie ${ }^{6}$, Getachew Tollera', Ashenafi Assefa', Geremew Tasew ${ }^{1}$, Adugna Woyessa ${ }^{1}$ and Ebba Abate ${ }^{1}$

\begin{abstract}
Background: Encouraged by the previous success in malaria control and prevention strategies, the Ethiopian ministry of health launched malaria elimination with a stepwise approach by primarily targeting the lowtransmission Districts and their adjacent areas/zones in order to shrink the country's malaria map progressively. Hence, this community survey was conducted to establish baseline malaria information at the preliminary phase of elimination at targeted settings.

Methods: A community-based cross-sectional survey was conducted at 20 malaria-elimination targeted Districts selected from five Regional states and one city administration in Ethiopia. The GPS-enabled smartphones programmed with Open Data Kit were used to enumerate 9326 study households and collect data from 29,993

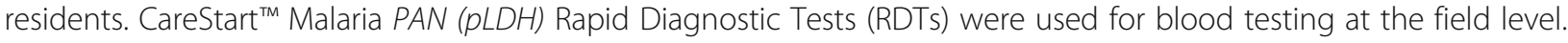
Armpit digital thermometers were used to measure axillary temperature.

Result: Overall malaria prevalence by RDTs was 1.17\% (339/28973). The prevalence at District levels ranged from 0.0 to $4.7 \%$. The proportion of symptomatic cases (axillary temperature $>37.5^{\circ} \mathrm{C}$ ) in the survey was $9.2 \%(2760 / 29993)$. Among the 2510 symptomatic individuals tested with RDTs, only 3.35\% (84/2510) were malaria positive. The $75.2 \%$ (255/339) of all malaria positives were asymptomatic. Of the total asymptomatic malaria cases, $10.2 \%$ (26/255) were under-five children and $89.8 \%$ (229/255) were above 5 years of age.

Conclusion: The study shows a decrease in malaria prevalence compared to the reports of previous malaria indicator surveys in the country. The finding can be used as a baseline for measuring the achievement of ongoing malaria elimination efforts. Particularly, the high prevalence of asymptomatic individuals (0.88\%) in these transmission settings indicates there may be sustaining hidden transmission. Therefore, active case detection with more sensitive diagnostic techniques is suggested to know more real magnitude of residual malaria in the elimination-targeted areas.
\end{abstract}

Keywords: Baseline survey, Malaria epidemiology, Malaria elimination, Ethiopia

\footnotetext{
* Correspondence: desalegn24@gmail.com

${ }^{\dagger}$ Desalegn Nega and Adugna Abera contributed equally to this work.

'Ethiopian Public Health Institute, Addis Ababa, Ethiopia

Full list of author information is available at the end of the article
}

(c) The Author(s). 2021 Open Access This article is licensed under a Creative Commons Attribution 4.0 International License, which permits use, sharing, adaptation, distribution and reproduction in any medium or format, as long as you give appropriate credit to the original author(s) and the source, provide a link to the Creative Commons licence, and indicate if changes were made. The images or other third party material in this article are included in the article's Creative Commons licence, unless indicated otherwise in a credit line to the material. If material is not included in the article's Creative Commons licence and your intended use is not permitted by statutory regulation or exceeds the permitted use, you will need to obtain permission directly from the copyright holder. To view a copy of this licence, visit http://creativecommons.org/licenses/by/4.0/ The Creative Commons Public Domain Dedication waiver (http://creativecommons.org/publicdomain/zero/1.0/) applies to the data made available in this article, unless otherwise stated in a credit line to the data. 


\section{Introduction \\ Background}

During the last decade, substantial worldwide progress has been made in controlling malaria worldwide. The magnitude of the progress has led some malaria-endemic countries to consider the possibility of malaria elimination [1-4]. Ethiopia experienced cycles of major malaria epidemics every 5 to 8 years in highland areas, where the last nationwide epidemic (> 4000 malaria deaths) occurred in 2003 and fewer epidemics since 2004 [5]. The apparent decrease of major malaria epidemics within the last decade is a result of the national scale-up of malaria control interventions in Ethiopia $[5,6]$. Mass distribution of insecticide-treated bed nets (ITNs), indoor residual spraying (IRS), and adoption of Artemisinin-based combination therapy (ACT) contributed much to the substantial declines in malaria-related deaths and morbidity $[5,7,8]$.

In its current national malaria strategic plan 20212025 [9] and in its malaria elimination roadmap [10], Ethiopia declared to achieve national-level malaria elimination in 2030, by prioritizing elimination in targeted low transmission settings and preventing the reintroduction of malaria into Districts reporting zero indigenous malaria cases. Since a decrease in malaria burden noted earlier is not uniform, a sub-national elimination must be attempted before nationwide elimination can be attained [10]. Thus, the country aims to eliminate malaria with a stepwise approach by targeting first the lowtransmission Districts (Districts below five cases per 1000 people per year) and their adjacent areas/zones to shrink the country's malaria map progressively [11].

Several malaria epidemiological surveys have been carried out since 2000 in Ethiopia, with malaria prevalence by microscopy declining from 10.4 to $0.5 \%$ in 2015 [1214]. Some of the nationally-representative surveys were the Demographic and Health Survey (DHS) 2000 [15], DHS 2005 [16], a large survey by the Carter Center [17], the Ethiopia Malaria Indicator Survey (EMIS) 2007, MIS 2011, and MIS 2015 [18-20]. The various findings of these surveys have been reported extensively. Most of these surveys assessed key malaria interventions, treatment-seeking behavior, anemia prevalence in children $<5$ years of age (U5), malaria prevalence in all age groups, malaria knowledge among women, and indicators of socioeconomic status. The survey results were stratified by Regional states, by altitude, and by Districts. Compared to DHS 2005 [16], findings from MIS 2007, MIS 2011, MIS 2015 reflected the significant effort of the FMOH-led scale-up of malaria prevention and control interventions, with substantial increases in insecticide-treated net (ITN) ownership and use, as well as malaria knowledge.

The most recent survey, EMIS 2015, is a large, nationally representative survey of coverage of key malaria control interventions, treatment-seeking behavior, and malaria prevalence. EMIS 2015 also assessed anemia prevalence in children less than five years of age (U5), malaria knowledge among women, and indicators of socioeconomic status. EMIS 2015 similar to the previous EMISs focuses on areas < $2000 \mathrm{~m}$ above sea level (ASL). Differently from EMIS 2011, all Regions, including Dire Dawa City Administration and Harar Region, have separate Regional estimates.

The current survey is a baseline survey conducted in settings targeted for malaria elimination in specific geographies in Ethiopia. Baseline malaria information gathered at the pre-elimination phase is essential to understand the community-level transmission and measure the next outcomes towards the elimination goal. Baseline survey results enable programs (or program managers/interested people) to anticipate achievements and changes in the future regarding interventions administered for malaria prevalence reduction in the communities [21]. A baseline survey on malaria epidemiology and intervention coverage at the community level in the elimination-planned Districts would help to know the status in terms of parasite distribution, intervention coverage, and community awareness to malaria and control approaches, and to evaluate the success of activities exerted for elimination. Therefore, this study was conducted to measure the magnitude of Plasmodium infections at the community level in the initial phase of malaria elimination in the targeted Districts and Regions in Ethiopia.

\section{Materials and methods}

\section{Study area and period}

This study was conducted from October to December 2018 in selected Districts targeted for malaria elimination in Ethiopia. Ministry of Health $(\mathrm{MOH})$ launched malaria elimination in 239 Districts with low annual parasites among the five Regional states (Amhara, South Nations and Nationalities, Oromia, Tigray, and Harari Regions) and Dire-Dawa city administration. Ethiopia National Strategic Plan (NSP) 2017-2020 has stratified the country's malaria situation based on Annual Parasite Incidence (API) per 1000 population. Accordingly, four broad strata have been identified. They are malaria-free (API $=0)$, low (API $=>0$ to $\leq 10$ cases $/ 1000$ person-years), moderate (API $=>10$ to $<50$ cases), and high-transmission (API = $\geq 50$ cases/1000 person-years) strata. The current assessment was commenced in these low-to-moderate malaria transmission Districts in Ethiopia as shown in Fig. 1.

The selected study Districts were from Amhara Region (Berehet, Raya kobo, Bugna, Habru); from Oromia Region (Merti, Sire, Zeway-Dugida, Kersa, Gemechis); from South Ethiopia (Dilla-zuria, Marako, Misrak-Badawacho, Damboya, Dore, Lanfaro); from Tigray Region (KollaTembein, Hawzen, Seharti-samre), and all Districts in Diredawa city administration and Harari Region. 


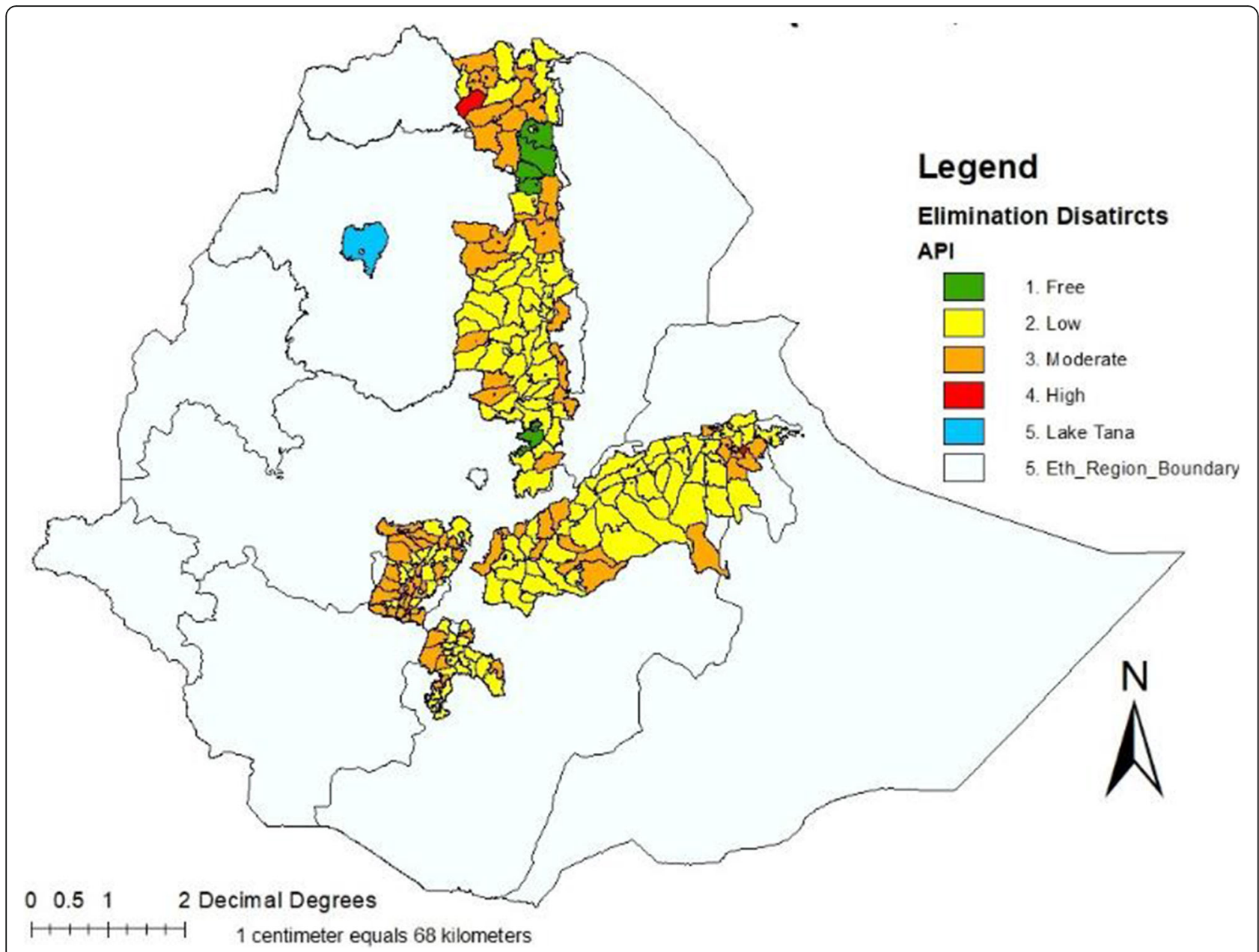

Fig. 1 Risk map of Districts by annual parasite incidence, Ethiopia, 2017 (Source FMOH malaria NSP: 2017-2020)

\section{Study participants}

All members of the selected households in the study Districts, those with or without malaria symptoms, aged above 1 year and both sexes were included. Individuals having taken anti-malarial drugs in the past six weeks, non-consenting individuals, children under the age of one year, and absentees at home during data collection were excluded.

\section{Study design and sampling procedure}

The design of the study was cross-sectional. From among the 239 malaria elimination target districts, only 20 districts were selected as study districts proportionally considering the total size of elimination target districts per each region/city administration, intended study objective, higher malaria reports, the average population per district, and available budget. The sample design was framed by Ethiopian Central Statistical Agency (CSA), in collaboration with data management professionals in Ethiopian Public Health Institute
(EPHI). The sampling frame used for this survey was a list of malarious kebeles in the selected 20 target districts (domains) selected for the study. In each domain (district), a sample of kebeles with a predetermined sample size was then selected independently with probability proportional to size. A two-stage cluster sampling was used where kebele was the primary sampling unit and the household was the second-stage sampling unit. The design of the survey was cross-sectional and the minimum sample size required for the survey, per domain, was determined using the formula below: $\mathrm{n}$ $=\operatorname{Deft}^{2}\left(z \frac{a}{2}\right)^{2}\left[\frac{p(1-p) x^{2}}{d^{2}}\right]$.

Where, $\boldsymbol{n}$ : the required minimum sample size per domain; $\boldsymbol{\alpha}$ : level of significance; $\boldsymbol{p}$ : prevalence rate; $\boldsymbol{d}$ : absolute precision $\left(=2^{*} \mathrm{p}^{*} \varepsilon\right)$; $\boldsymbol{\varepsilon}$ : desired relative standard error; Deft: estimated design effect to account for the twostage cluster sampling method.

The key indicator taken to determine the sample size was malaria parasite prevalence by microscopy, which 
was $0.5 \%$, among all age groups residing in malarious areas according to the Ethiopia National Malaria indicator survey 2015. In the above formula, using a relative precision of $0.4 \%, 0.05$ level of significance, design effect of 1.3 , and adjusting for the $97 \%$ household gross response rate, and taking 20 domains (districts), the total minimum sample size was 9326 households, and 112 kebeles from a total of 406 malarious kebeles in the 20 study districts.

Households were selected with a simple random sampling using EPiSample software programmed in smartphones. To have had a domain-level estimate, precision and design effect were used at district levels. The distribution of the total sample size to the districts; therefore, used a power allocation with an appropriate power value of 0.99 to guarantee a sufficient sample size in small districts.

\section{Field data collection}

During fieldwork, field teams conducted full household listings in each kebele/village using the smartphones programmed with EpiSample software [22] and selected randomly the study households with the support of field technical assistants and guide persons. Questionnaires were programmed into Samsung I9300 S3 Neo smartphones with a capacity of taking global positioning system (GPS) at each household level. After obtaining consent from the study participants, a face-to-face questionnaire interview was held by health officers/nurses. The participants were interviewed for any malaria-like symptom or fever with in past $48 \mathrm{~h}$ before study commencement. Armpit digital thermometers were used to measure the axillary temperature. Laboratory technologists conducted testing of finger-prick blood by Care Start $^{\text {tw }}$ Malaria PAN ( $\left.p L D H\right)$ Ag Rapid Diagnostic Tests (RDTs) [23]. Field data collected by EpiSample were every day sent to the central EPHI data management server and backup data was downloaded from the internet server to a computer every week.

\section{Statistical analysis of data}

Data were cleaned and analyzed using STATA 14 package [24]. Descriptive statistics were used to describe the characteristics of the sample and calculate coverage, use, and access estimates. Point estimates and confidence intervals were analyzed to adjust clustering in the sampling design, with weighting for household and cluster sampling probability [25]. The descriptive statistics and differences in distribution were evaluated using the Chi-square $\left(x^{2}\right)$ test and $P$-value $<0.05$ was considered statistically significant.

\section{Definition of terms}

\section{Asymptomatic malaria}

Are cases tested positive by malaria RDTs but were with an axillary temperature of $<37.5^{\circ} \mathrm{C}$ as measured by a digital thermometer or/and those who had reported no fever history or no malaria-like symptoms within $48 \mathrm{~h}$ before field data collection.

\section{Symptomatic malaria}

Are cases tested positive by malaria RDTs, and had an axillary temperature of $\geq 37.5^{\circ} \mathrm{C}$ as measured by a digital thermometer or/and had fever history or other malarialike symptoms within $48 \mathrm{~h}$ before field data collection.

\section{Results}

\section{Characteristics of the study population}

This baseline assessment was conducted in twenty malaria elimination targeted Districts, selected from five Regions and one city administration. The Regions are Harar, Oromia, Amhara, Southern Nations Nationalities and Peoples (SNNP), and Tigray Regions; and Dire Dawa city administration. At the total study households, 35,900 participants were initially registered into the ODK program installed in the Smartphone; of which, 29,993 gave axillary temperature for temperature measurement. Out of those who gave axillary temperature, 28,973 participants tested for malaria with RDTs (Table 1).

The mean age of participants was 25 years(yrs). An age category of 18-59 yrs held the highest proportion (44.8$61.8 \%$ ) in all the study Regions; while, the age category of $>60$ yrs covered the lowest proportion in all Regions. The other age groups covered almost a similar proportion in all settings. Gender data showed almost equal proportion in all study settings, despite a slight increase by female participants in some areas (Table 1).

\section{Malaria prevalence per regions}

The overall prevalence of malaria as detected by RDTs in this survey was $1.17 \%(339 / 28983)$ among the total study participants. A high proportion of malaria infection was reported from Harari $46(4.7 \%)$ followed by $87(3.7 \%)$ in Kersa, 81(2.7\%) in Misrak Badawacho, 27(1.7\%) in Kolla Tembien, 32(1.4\%) in Habru and 22(1.07\%) in Raya Kobo Districts. In half (50\%) of the surveyed Districts, the prevalence of malaria was in between greater zero $\&<1 \%$ by RDTs. Interestingly, four Districts namely Berehet, Sire, Gemechis, and Damboya reported zero prevalence of malaria by the RDTs (Table 2).

\section{Malaria and socio-demographic characteristics}

From a total of 28,983 survey participants who were grouped into five age groups, malaria prevalence was highest among the age group 5-11 yrs (1.8\%) followed by $12-17$ yrs $(1.4 \%)$, while malaria prevalence was lowest among the age group of $18-59$ yrs $(0.9 \%)$. Malaria prevalence rate among males (1.4\%) was higher than females (1\%) (P-value <0.001). Malaria prevalence among 
Table 1 Characteristics of study sites and population by Regions in Ethiopia, Oct-Dec 2018

\begin{tabular}{lllllllll}
\hline Characteristics & Amhara, N (\%) & Dire dawa N (\%) & Harari N (\%) & Oromia, N (\%) & SNNPR, N (\%) & Tigray, N (\%) & Total, N (\%) \\
\hline Age in yrs & $<5$ & $609(9.6)$ & $145(12)$ & $65(6.1)$ & $1245(13.2)$ & $1533(12.1)$ & $461(9.7)$ & $4058(11.4)$ \\
& $5-11$ & $940(14.7)$ & $213(17.7)$ & $174(16.4)$ & $1726(18.3)$ & $3126(24.7)$ & $903(19)$ & $7082(20)$ \\
& $12-17$ & $679(10.6)$ & $112(9.3)$ & $102(9.6)$ & $1049(11.1)$ & $1884(14.9)$ & $569(12)$ & $4395(12.4)$ \\
& $18-59$ & $3699(58)$ & $667(55.3)$ & $656(61.8)$ & $4697(49.7)$ & $5659(44.8)$ & $2317(48.8)$ & $17,695(49.9)$ \\
& $>60$ & $449(7)$ & $69(5.7)$ & $64(6)$ & $729(7.7)$ & $439(3.5)$ & $499(10.5)$ & $2249(6.3)$ \\
Sex & Female & $3277(50.6)$ & $673(53.5)$ & $525(48.4)$ & $4684(49.3)$ & $6582(51.5)$ & $2360(49.5)$ & $18,101(50.4)$ \\
& Male & $3203(49.4)$ & $586(46.5)$ & $558(51.5)$ & $4821(50.7)$ & $6208(48.5)$ & $2407(50.5)$ & $17.783(49.6)$ \\
\multirow{5}{*}{ Fever } & No & $5563(98.2)$ & $917(99.2)$ & $997(96.1)$ & $7861(99.3)$ & $7798(76.1)$ & $4091(97.5)$ & $27.227(90.8)$ \\
& Yes & $102(1.8)$ & $7(0.8)$ & $41(3.9)$ & $58(0.7)$ & $2453(23.9)$ & $105(2.5)$ & $2766(9.2)$ \\
\hline
\end{tabular}

pregnant women $(1.9 \%)$ was higher compared to nonpregnant women (P-value: 0.023$)$ (Table 3$)$.

Among the 2510 symptomatic individuals having axillary temperature $>37.5^{\circ} \mathrm{C}$, only $84(3.35 \%)$ were malaria positive while 2426 (96.65\%) were malaria negative.
There was a significant association between fever and malaria positivity $(P$-value $<0.001)$ (Table 3$)$. Among the total study participants, malaria prevalence in asymptomatic individuals was $0.88 \%(255 / 28973)$ and in symptomatic individuals was $0.29 \%(84 / 28973)$. Among all

Table 2 Prevalence of malaria using RDTs by Regions and Districts in Ethiopia, October to December 2018

\begin{tabular}{|c|c|c|c|c|}
\hline \multirow[t]{2}{*}{ Regions } & \multirow[t]{2}{*}{ Name of Districts } & \multicolumn{3}{|l|}{ RDT Results } \\
\hline & & Total, n (\%) & Positive, n(\%) & 95\% Cl for Positives \\
\hline \multirow[t]{5}{*}{ Amhara } & Berehet & $531(100))$ & 0 & $0.0-0.69$ \\
\hline & Bugina & $626(100$ & $1(0.16)$ & $0.0-0.89$ \\
\hline & Raya kobo & $2055(100)$ & $22(1.07)$ & $0.67-1.62$ \\
\hline & Habru & $2281(100)$ & $32(1.4)$ & $0.96-1.97$ \\
\hline & Total & $5493(100)$ & $55(1)$ & $0.76-1.3$ \\
\hline Dire dawa & & $886(100)$ & $4(0.45)$ & $0.12-1.15$ \\
\hline Harari & & $979(100)$ & $46(4.7)$ & $3.46-6.22$ \\
\hline \multirow[t]{6}{*}{ Oromia } & Merti & $871(100)$ & $8(0.92)$ & $0.4-1.8$ \\
\hline & Sire & $729(100)$ & 0 & $0.0-0.5$ \\
\hline & Zeway-dugida & $2433(100)$ & $10(0.41)$ & $0.2-0.75$ \\
\hline & Kersa & $2358(100)$ & 87 (3.69) & $2.97-4.53$ \\
\hline & Gemechis & $1447(100)$ & 0 & $0.0-0.25$ \\
\hline & Total & $7838(100)$ & $105(1.34)$ & $1.1-1.62$ \\
\hline \multirow[t]{7}{*}{ SNNPR } & Dilla-zuria & $503(100)$ & $2(0.4)$ & $0.05-1.43$ \\
\hline & Marako & $1816(100)$ & $1(0.06)$ & $0.0-0.31$ \\
\hline & Misrak-badawacho & $2999(100)$ & $81(2.7)$ & $2.15-3.35$ \\
\hline & Damboya & $816(100)$ & 0 & $0.0-0.45$ \\
\hline & Dore (Hawassa-zuria) & $1403(100)$ & $1(0.07)$ & $0.0-0.40$ \\
\hline & Lanfaro & $2129(100)$ & $1(0.05)$ & $0.0-0.26$ \\
\hline & Total & $9666(100)$ & $86(0.9)$ & $0.71-1.1$ \\
\hline \multirow[t]{4}{*}{ Tigray } & Kolla-Tembein & $1597(100)$ & $27(1.69)$ & $1.12-2.45$ \\
\hline & Hawzen & $1235(100)$ & $5(0.4)$ & $0.13-0.94$ \\
\hline & Seharti-Samre & $1289(100)$ & $11(0.9)$ & $0.43-1.52$ \\
\hline & Total & $4121(100)$ & $43(1.04)$ & $0.76-1.4$ \\
\hline Total & & $28,973(100)$ & $339(1.17)$ & $1.05-1.3$ \\
\hline
\end{tabular}

$\mathrm{Cl}=\boldsymbol{P} \pm \mathbf{z} \sqrt{\boldsymbol{P}(\mathbf{1}-\boldsymbol{P}) / \boldsymbol{n}}$; where $\mathbf{z}$ value for $95 \%=1.96, \mathbf{p}=$ sample proportion, $\mathbf{n}=$ sample size, $\mathbf{C l}=$ confidence interval 
Table 3 Malaria prevalence and sociodemographic characteristics in Ethiopia, October to December 2018

\begin{tabular}{|c|c|c|c|c|}
\hline \multirow[t]{2}{*}{ Characteristics } & \multicolumn{3}{|l|}{ RDT results } & \multirow{2}{*}{$\begin{array}{l}\text { P- } \\
\text { value }\end{array}$} \\
\hline & Total & Positive & $95 \% \mathrm{Cl}$ & \\
\hline \multicolumn{5}{|l|}{ Age group (in years) } \\
\hline$<5$ & $2886(100)$ & $36(1.25)$ & $0.87-1.72$ & 0.677 \\
\hline $5-11$ & $5963(100)$ & $107(1.79)$ & $1.47-2.16$ & 0.044 \\
\hline $12-17$ & 3535 (100) & $50(1.41)$ & $1.05-1.86$ & 0.354 \\
\hline $18-59$ & $14,703(100)$ & $125(0.85)$ & $0.71-1.01$ & 0.251 \\
\hline >60(Reference) & $1886(100)$ & $21(1.1)$ & $0.69-1.7$ & \\
\hline Total & $28,973(100)$ & $339(1.17)$ & $1.05-1.30$ & \\
\hline \multicolumn{5}{|l|}{ Sex } \\
\hline Female (Reference) & $15,566(100)$ & $149(0.96)$ & $0.81-1.12$ & \\
\hline Male & $13,407(100)$ & $190(1.42)$ & $1.22-1.63$ & $<0.001$ \\
\hline Total & $28,973(100)$ & $339(1.17)$ & $1.05-1.30$ & \\
\hline \multicolumn{5}{|l|}{ Pregnant Women } \\
\hline Yes & $514(100)$ & $10(1.95)$ & $0.94-3.55$ & 0.023 \\
\hline No (Reference) & $7590(100)$ & $58(0.76)$ & $0.58-0.99$ & \\
\hline Don't Know & $36(100)$ & 0 & $0.0-9.74$ & 0.988 \\
\hline Total & $8140(100)$ & $68(0.84)$ & $0.65-1.06$ & \\
\hline \multicolumn{5}{|l|}{ Travel History (in the last 3 months), $n$ (\%) } \\
\hline Yes & $418(100)$ & $7(1.67)$ & $0.68-3.42$ & 0.274 \\
\hline No & $25,617(100)$ & $283(1.1)$ & $0.98-1.24$ & Ref \\
\hline Total & $26,035(100)$ & $290(1.1)$ & $0.99-1.25$ & \\
\hline \multicolumn{5}{|l|}{ Fever status, n (\%) } \\
\hline Symptomatic (axillary temp> 37.5oC) & $2510(100)$ & $84(3.35)$ & $2.68-4.13$ & $<0.001$ \\
\hline Non-symptomatic (axillary temp $\leq 37.5 \circ$ C) & $26,463(100)$ & $255(0.96)$ & $0.85-1.09$ & Ref \\
\hline Total & $28,973(100)$ & $339(1.17)$ & $1.05-1.30$ & \\
\hline \multicolumn{5}{|l|}{ The altitude of the study area (M), n(\%) } \\
\hline $1000-1500$ & $3095(100)$ & $65(2.1)$ & $1.62-2.67$ & $<0.001$ \\
\hline $1501-2000$ & $18,834(100)$ & $167(0.89)$ & $0.76-1.03$ & 0.043 \\
\hline$>2000$ & $3453(100)$ & $51(1.48)$ & $1.1-1.94$ & Ref \\
\hline Total & 25,382 (100) & $283(1.11)$ & $0.99-1.25$ & \\
\hline
\end{tabular}

malaria positives, $75.2 \%(255 / 339)$ were asymptomatic and $24.8 \%(84 / 339)$ were symptomatic (Table 3$)$.

The highest malaria prevalence was seen at the lower altitude (1501-2000 m) above sea level (ASL), while less prevalence occurred at $>2000 \mathrm{~m}$. There was observed a significant relationship between lower altitude and malaria prevalence (P-value <0.001). The assessment showed travel history (within the last 3 months) had no association (P-value: 0.274 ) with malaria positivity. Most of the malaria positives had no travel history. Of those having travel history within the last 3 months, $98.3 \%$ (418) were malaria negative while only $1.7 \%$ were malaria positive (Table 3 ).

Where; ref: reference, CI: Confidence Interval, n: sample size
Among the asymptomatic malaria patients (255), the highest proportion was observed in $18-59$ yrs of age, which was $38.4 \%(98)$; followed by $29.4 \%(75)$ in $5-11 \mathrm{yrs}$, $16.1 \%(41)$ in $12-17 \mathrm{yrs}, 10.5 \%(26)$ in under $5 \mathrm{yrs}$, and $5.9 \%(15)$ in $>60 \mathrm{yrs}$ of age. This means asymptomatic malaria prevalence was $10.2 \%(26 / 255)$ in under-five children and $89.8 \%(229 / 255)$ in age groups above 5 yrs (Table 3).

\section{Discussion}

The current study provided baseline information for the malaria elimination program in the targeted low transmission Districts of Ethiopia. The overall prevalence of malaria by RDT in this survey was $1.17 \%$ (339/28973). In this survey, malaria prevalence ranged from zero to $4.7 \%$ at the District level by RDTs. In half $(50 \%)$ of the 
surveyed Districts, malaria prevalence was above zero and less than $1 \%$ by RDTs. This decreasing malaria is supported by the previous Regional level malaria prevalence reports in Ethiopia [12-14] and also by the findings of Ethiopian national-level malaria indicator surveys of 2007, 2011, and 2015 [18-20]. Although the current baseline survey was conducted in the targeted five Regions and in one city administration different from the national malaria indicator surveys (MIS) which were conducted in all nine regions in the country, we tried to compare the current malaria prevalence with previous reports. Figure 2 shows a trend in malaria prevalence among the Ethiopian MIS 2007, MIS 2011, and MIS 2015, and in the present malaria elimination-baseline survey by RDTs. There was a decrease in malaria prevalence by RDTs in the current study (1.17\%) compared to the results of MIS 2015 (1.2\%), and MIS 2011 (4.5\%) (Fig. 2).

There were observed changes in malaria prevalence among Regions between MIS 2015 and the current baseline survey. A decrease in malaria prevalence occurred in Tigray and Amhara Regions; while, a little increase in malaria was seen in Oromia, Southern Nations, and Nationalities of Peoples Region (SNNPR) and Dire Dawa City Administration between MIS 2015 and the current baseline survey. Malaria increased from 1.9 to $4.7 \%$ in Harari Region between EMIS 2015 and the current survey (Fig. 3). The decrease in malaria prevalence in some Regions shows the strong and continuous malaria intervention approaches in these Regions; while, increased malaria prevalence in other Regions might have occurred due to several reasons such as gaps in malaria control and prevention interventions, changes in climatic conditions and parasitic factors. Another possible reason for the fluctuation of malaria transmission in Ethiopia might be the unstable nature of malaria transmission at diverse geographies of the country. In Ethiopia, there are low malaria cases in a given year and also there may be high malaria reports in another year at a similar set up [26].

Malaria prevalence was higher among the age group $5-11$ years $(1.8 \%)$ followed by $12-17$ years $(1.4 \%)$, while the prevalence rate was low among the age group of 18 59 years $(0.9 \%)$. However, the difference in malaria prevalence among age groups was not significant. Among the total asymptomatic malaria patients (255), the highest proportion was observed in $18-59$ yrs. of age, which was $38.4 \%$ (98). Asymptomatic malaria prevalence was $10.2 \%(26 / 255)$ in under-five children and $89.8 \%(229 / 255)$ in age groups above 5 years. This may be so because the older ages might have developed acquired immunity from repeated previous exposures that could block malaria symptom development as reported by other studies [27].

There was a little increase in malaria prevalence among males (1.4\%) than females (1\%). Males usually stay in outdoor activities more frequently than females and hence are more exposed to mosquito bites. Currently, studies reported that mosquitoes change their behavior from indoor biting to outdoor, or probably new mosquitoes with outdoor biting may have arrived at the study areas [28]. The current malaria prevention and control intervention program gives higher priority for pregnant women and children; however, malaria prevalence among pregnant women (1.9\%) was higher when compared to non-pregnant women and those who did

\section{Trend in malaria prevalence by RDTs}

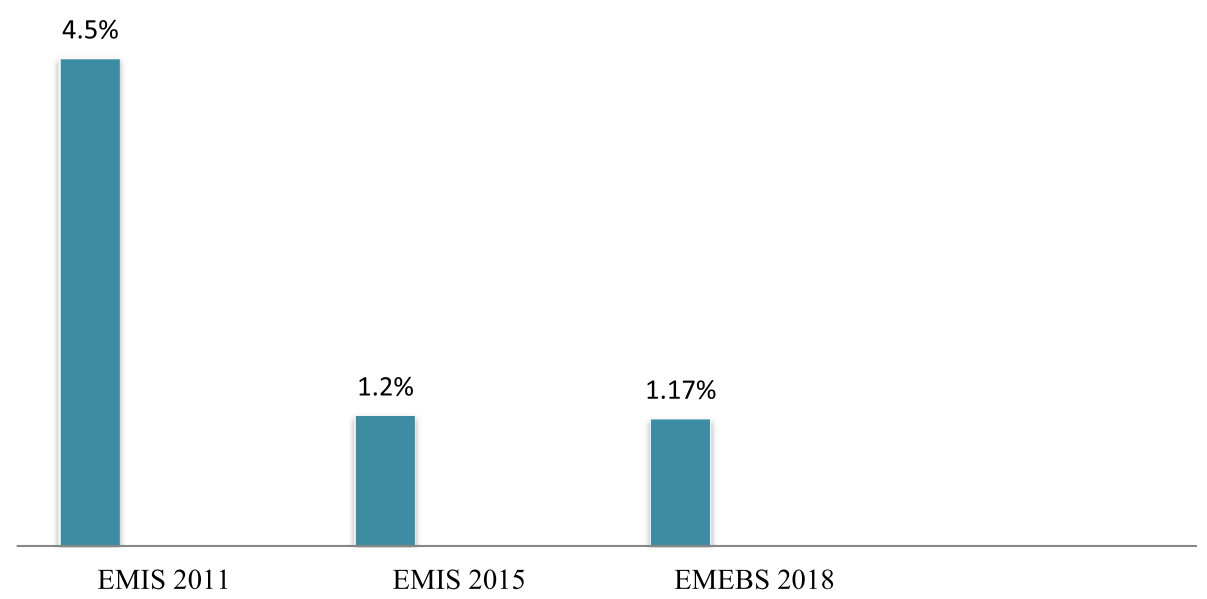

Fig. 2 Trends in malaria prevalence by RDTs: Ethiopia MIS 2011, MIS 2015, and the current Malaria elimination baseline survey 2018. Where EMIS: Ethiopian malaria indicator survey; EMEBS: Ethiopian malaria elimination baseline survey 


\section{Trend in malaria prevalence of regions by RDTs between EMIS 2015 \& EMEBA 2018}

-EMIS2015 —EMEBS2018

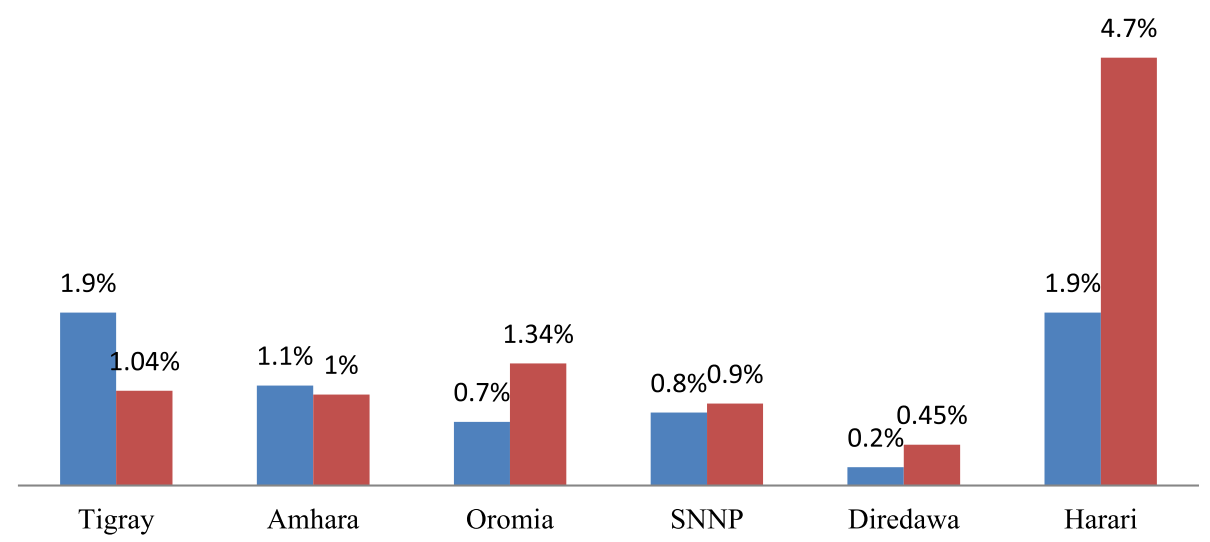

Fig. 3 Malaria prevalence among all ages by RDTs in EMIS 2015 and EMEBA 2018. Where, EMEBS: Ethiopian malaria elimination baseline survey, SNNP: Southern nations, nationalities and peoples' Region

not know their pregnancy status. A possible reason for this may be immune suppression and loss of acquired immunity among the pregnant and the hormonal, immunological, and hematological changes during the pregnancy period [29]. High malaria prevalence (59\% of all positives) was seen at an altitude of 1501$2000 \mathrm{~m}$ ASL, while $23 \%$ at $1000-1500 \mathrm{~m}$ and $18 \%$ at > $2000 \mathrm{~m}$. There was a significant relationship between lower altitude and malaria positivity as stated by another study [30].

In this study, among the 2510 symptomatic individuals having axillary temperature $>37.5^{\circ} \mathrm{C}$, only $84(3.35 \%)$ were malaria positive while 2426 (96.65\%) were negative. This may be so because fever is not specific to malaria and it might have been caused by other illnesses. Fever was not fully explained by malaria as reported by other studies in low-resource areas [31]. Although the proportion of infection was lower among symptomatic cases, there was a significant association between fever and malaria positivity.

Asymptomatic malaria cases accounted for 0.88\% (255/ 28973) among the total tested study participants and $75.2 \%$ (255/339) among all malaria positives. The asymptomatic malaria cases in low transmission and elimination-targeted areas are potential reservoirs sustaining uninterrupted malaria transmission in the area [32]. Concerning the elimination strategy, WHO remarks that asymptomatic malaria infections should be confirmed by standard diagnostic tests. WHO states that any case confirmed by a diagnostic test is malaria infection whether it is symptomatic or asymptomatic. Active monitoring of malaria infections is necessary for settings where malaria transmission has currently declined and national efforts are underway to achieve malaria elimination.
In Zambia [33], among 3863 household members tested in the elimination target areas, $2.6 \%$ of individuals were found positive by either of RDTs, microscopy, or PCR. Of all positives, $47 \%$ (48) had sub-patent parasitemia and 85\% of sub-patent parasitemia cases were asymptomatic. The study recommended further need of active or reactive case detection approaches to identify more asymptomatic individuals at the community levels during declining malaria. Most countries with low transmission settings and striving to eliminate malaria demonstrated a large proportion of asymptomatic Plasmodium infections, particularly submicroscopic parasitemia cases [34-36]. Asymptomatic and subpatent malaria reservoirs can maintain continuous transmission even in low transmission settings unless they are strictly monitored and detected by a highly sensitive diagnostic method, and immediately treated by an effective antimalarial drug [37]. The current study findings forward the necessity of the use of more sensitive molecular diagnostic tools to give a more accurate prevalence of infections in community surveys occurring in lowtransmission settings.

The large-scale deployment of RDTs for malaria diagnosis has greatly improved access to confirmatory diagnosis in malaria-endemic countries, contributing to the success of malaria control programs in recent years [38]. RDTs are convenient tests for the screening of a large number of samples in national surveillance studies or other largescale malaria elimination programs such as mass screening and treatment programs. However, population surveys using traditional diagnostic techniques including microscopy or RDTs may miss submicroscopic infections that are below the detection limit of these tools. Studies in high transmission areas have shown that as many as two-thirds 
of microscopy-negative patients may have low-grade parasites [39].

False-negative RDT results commonly occur because of professional errors, inconvenient storage situations, histidine-rich protein deletions, low parasitemia, and RDT types with poor performance. The detection capacity of malaria RDTs varies in different transmission settings and false-negative RDT results are common in lower malaria transmission settings [40]. Therefore, highly sensitive and specific malaria diagnostics such as PCR or highly sensitive RDTs are critically needed in community surveys, particularly in low transmission and elimination target settings to explore more precise prevalence estimates [41].

\section{Strengths and limitations of the study}

Although this paper has placed malaria prevalence by RDTs only, this study incorporated a multistage sampling design, used the Smartphones programmed with the ODK based technology for questionnaire interview and household selection, and employed a consolidated efforts of several partner organizations to collect a very large size malaria data. For the quality of data, fieldcollected data in ODK were daily sent to EPHI online data depository server. Several governmental and nongovernmental partner organizations, working on malaria control and elimination, participated in the accomplishment of this baseline survey. Because of lack of reagents, the molecular level prevalence of sub-patent malaria was not done despite a large number of dried blood spots collected in this baseline survey.

\section{Conclusion}

The total malaria prevalence by RDTs in this survey was $1.17 \%$; of which, $0.29 \%$ were symptomatic and $0.88 \%$ were asymptomatic. The current finding showed a decrease in malaria prevalence compared to the reports of previous malaria surveys in the country and can be used as a baseline for measuring the achievement of ongoing malaria elimination activities. These infections in low transmission and elimination-targeted areas are highly considerable since they may still sustain an uninterrupted malaria transmission in the area. Although RDTs may be convenient serological tests for the screening of a large number of samples in national surveillance studies or other largescale malaria elimination programs such as mass screening and treatment programs, population surveys using traditional diagnostic techniques including microscopy and/or RDTs may miss submicroscopic infections that are below the detection limit of these tools. Therefore, molecular techniques are more sensitive and thus are more likely to detect sub-patent infectious reservoirs in the elimination settings.

\section{Abbreviations}

ACT: Artemisinin Based Combination Therapy; API: Annual Parasite Incidence; EPHI: Ethiopian Public Health Institute; FMOH: Federal Ministry of Health; HH: Household; HMIS: Health Management Information System; IRS: Indoor Residual Spraying; ITN: Insecticidal Treated Net; LLIN: Long Lasting Insecticidal Treated Net; MIS: Malaria Indicator Survey; NSP: National Strategic Plan; ODK: Open Data Kit; PCR: Polymerase chain reaction; RDT: Rapid Diagnostic Test

\section{Acknowledgments}

The Ethiopia Public Health Institute (EPHI) centrally coordinated the study; The Federal Ministry of Health (FMOH) organized the fund sponsorship (Global Fund) and technically supported the study. Central statistical agency (CSA) Ethiopia prepared study design and sampling procedures. Addis Continental Institute of Public Health (ACIPH), Malaria Control and Elimination Partnership in Africa (MACEPA) at PATH, Clinton Health Access Initiative, Inc. (CHAl), President's Malaria Initiative (PMI)/United States Agency for International Development (USAID), and World Health Organization (WHO) Ethiopia contributed technically in the execution of this study.

\section{Authors' contributions}

$\mathrm{D}_{s} \mathrm{~N}$ and $\mathrm{A}_{d} \mathrm{~A}$ : Conceptualization, designing, data collection, analysis, writeups \& coordination. BG, SM, $A_{b} A, D D$, and DM: Conceptualization, designing, data collection \& analysis. GA, SH, MH, KE, AY, and AG: Designing \& data collection. $H N, S A, D_{n} N, Z D$, and BS: Sampling procedure, ODK programming \& data analysis. $H T, G_{z} T, B T, H R, W B, A Z, A_{s} A$ and AW: Designing. $H S, G_{r} T, G_{t} T$ and EA: Designing \& survey management. $\mathrm{D}_{\mathrm{s}} \mathrm{N}$ wrote the final manuscript. All authors read and approved the final manuscript.

Where, $D_{s} N$ :Desalegn Nega; $D_{n} N$ : Daniel Nigatu; $A_{d} A:$ Adugna Abera; $A_{b} A: A b i n e t$ Abebe; $A_{s} A:$ Ashenafi Assefa; $G_{z} T: G e z a h a g n$ Tesfaye; $G_{r} T: G e r e m e w$

Tasew; G $T$ :Getachew Tollera.

\section{Funding}

Financial support was obtained from the National Malaria Control and Elimination Program; from Global Fund to Fight AIDS, Tuberculosis, and Malaria (GFATM). The funder had no role in the study design, data collection, and analysis, decision to publish, or preparation of the manuscript.

\section{Availability of data and materials}

The datasets used and/or analyzed during the current study are available from the corresponding author on reasonable request or are available in the EPHI data repository

\section{Declarations}

\section{Ethics approval and consent to participate}

This study was ethically cleared by the Institutional Review Board of the Ethiopian Public Health Institute (EPHI-IRB), with a reference number of EPHI $6.13 / 694$. The study was carried out per relevant guidelines and regulations. Informed consent was taken from adult participants as well from parents and/or legal guardians in the case of minor participants before administering the questionnaires and collecting blood samples. Professionally qualified public health nurses conducted household questionnaire interviews; while, medical laboratory technologists collected blood samples from the participants for malaria examination. Although the pain is already minor, blood samples were obtained only by a single finger pricking to minimize the risks of pain at the fingertip extremely lower. To keep confidentiality, study participants' data were coded separately and were accessed by the principal investigator (with permission of $\mathrm{Pl}$ ) only. All individuals found positive on RDTs at the field were treated according to the national malaria treatment guidelines $[42,43]$. People declared negative by RDT but who were symptomatic or otherwise ill were referred to the nearest health facilities for further investigation.

Consent for publication

Not applicable, the manuscript does not contain data from any person.

Competing interests

The authors declare that they have no competing interests. 


\section{Author details}

${ }^{1}$ Ethiopian Public Health Institute, Addis Ababa, Ethiopia. ${ }^{2}$ Federal Ministry of Health, Addis Ababa, Ethiopia. ${ }^{3}$ Central Statistical Agency, Addis Ababa, Ethiopia. ${ }^{4}$ Malaria Control and Elimination Partnership in Africa (MACEPA) at PATH, Addis Ababa, Ethiopia. ${ }^{5}$ President's Malaria Initiative (PMI), Addis Ababa, Ethiopia. ${ }^{6}$ Addis Continental Institute of Public Health, Addis Ababa, Ethiopia. ${ }^{7}$ Clinton Health Access Initiative, Inc. (CHAl), Addis Ababa, Ethiopia. ${ }^{8}$ World Health Organization (WHO), Addis Ababa, Ethiopia.

\section{Received: 28 January 2021 Accepted: 18 October 2021}

\section{Published online: 03 November 2021}

\section{References}

1. Asih PB, Rozi IE, Herdiana PNR, Hidayati AP, Marantina SS, et al. The baseline distribution of malaria in the initial phase of elimination in Sabang municipality, Aceh Province, Indonesia. Malar J. 2012;11(1):291. https://doi. org/10.1186/1475-2875-11-291.

2. Wang RB, Zhang J, Zhang QF. Malaria baseline survey in four special regions of northern Myanmar near China: a cross-sectional study. Malar J. 2014;13(1): 302. https://doi.org/10.1186/1475-2875-13-302.

3. Zhou Ti-Caol, Zhang Yi, Deng Yong ZS. Baseline survey of malaria elimination in Shaanxi Province. Exp Study. 2014;14: 1197-1199.

4. Reid H, Vallely A, Taleo G, Tatem AJ, Kelly G, Riley I, et al. Baseline spatial distribution of malaria prior to an elimination programme in Vanuatu. Malar J. 2010;9(1):150. https://doi.org/10.1186/1475-2875-9-150.

5. President's Malaria Initiative. Malaria Operational Plan FY 2014. Pres Malar Initiat Rwanda. 2013; 1-69. Available: http://www.pmi.gov/docs/defaultsource/default-document-library/malaria-operational-plans/fy14/zambia_ mop_fy 14.pdf?sfursn=8

6. WHO. World Health Organization. Country Programmes -WHO Ethiopia. Health topics/malaria.http://www.afro.who.int/en/ethiopia/country-progra mmes/topics/4580-ethiopia-malaria.html. Accessed May 14, 2015. 2015.

7. PMI. President's malaria initiative. Africa indoor residual spraying project. Ethiopia PMI country profile 2015. 2015. Available: http://www.africairs.net/ where-we-work/ethiopia/ Accessed on 4/28/15.

8. Charles M. Vector Control \& Entomology Scoping Report-Ethiopia. Integrated Vector Management (IVM) Task Order 2. Current status of entomological monitoring and surveillance for an effective delivery of vector control interventions in Ethiopia. April 2. 2006.

9. ETHIOPIA MALARIA ELIMINATION STRATEGIC PLAN: 2021 2025. Addis Ababa.

10. FMOH. Ethiopian National Malaria Elimination Roadmap 2016. 2016; 0-31.

11. FMOH. National Malaria Strategic Plan: 2014-2020, Federal Ministry of Health of Ethiopia, May 2014, Addis Ababa 2014.

12. Ashton RA, Kefyalew T, Tesfaye G, Pullan RL, Yadeta D, Reithinger R, et al. School-based surveys of malaria in Oromia regional state, Ethiopia: a rapid survey method for malaria in low transmission settings. Malar J. 2011;10(1): 211-9. https://doi.org/10.1186/1475-2875-10-25.

13. Emerson PM, Ngondi J, Biru E, Graves PM, Ejigsemahu Y, Gebre T, et al. Integrating an NTD with one of "the big three" combined malaria and trachoma survery in Amhara region of Ethiopia. PLoS Negl Trop Dis. 2008; 2(3):e197. https://doi.org/10.1371/journal.pntd.0000197.

14. Nosten F, McGready R. Burden of malaria during pregnancy in areas of stable and unstable transmission in Ethiopia during a nonepidemic year. J Infect Dis. 2003;188(8):1259-61. https://doi.org/10.1086/378678.

15. Koch DFA, Mcintyre RJ. The application of reflectance spectroscopy to a study of the anodic oxidation of cuprous sulphide. CSA. 1976;71(3):285-96. https://doi.org/10.1016/S0022-0728(76)80015-0.

16. Central Statistical Agency (CSA). Ethiopia Demographic and Health Survey, 2000. Heal San Fr. 2001 Nov. Available: http://www.measuredhs.com/pubs/ pub_details.cfm? ID=596\&srchTp=type\%5Cnhttp://scholar.google.com/ scholar?hl=en\&btnG=Search\&q=intitle: Ethiopia+Demographic+and+ Health+Survey\#4.

17. The Carter Center. Prevalence and Risk Facctors for Malaria and Trachoma in Ethiopia. The Carter Center, Ethiopia; 2007.

18. Jima D, Getachew A, Bilak H, Steketee RW, Emerson PM, Graves PM, et al. Ethiopia: coverage and use of major malaria prevention and control interventions. Malar J. 2007;9(1):58. https://doi.org/10.1186/1475-2875-9-58.

19. EHNRI. Ethiopia National Malaria Indicator Survey. 2011;2012:1-125.

20. Ethiopia National Malaria Indicator Survey 2015. Ethiopian Public Health Institute. Addis Ababa Ethiopia July 2016.
21. Babiker H, Ranford-Cartwright L, Sultan A, Satti G, Walliker D. Genetic evidence that $\mathrm{Rl}$ chloroquine resistance of plasmodium falciparum is caused by recrudescence of resistant parasites. Trans R Soc Trop Med Hyg. 1994; 88(3):328-31. https://doi.org/10.1016/0035-9203(94)90103-1.

22. EpiSample Guided Tour. https://docs.odk-x.org/episample-tour/.

23. WHO. Malaria Rapid Diagnostic Test Performance - results of WHO product testing of malaria RDTs: Round 1 (2008). Malar Rapid Diagnostic Test Perform - results WHO Prod Test Malar RDTs Round 1. 2009;4. doi:https:// doi.org/10.2471/tdr.09.978-924-1598071

24. STATA for Windows. https://www.stata.com/products/windows/.

25. Peterson I, Borrell LN, El-Sadr W, Teklehaimanot A. Individual and household level factors associated with malaria incidence in a highland region of Ethiopia: a multilevel analysis. Am J Trop Med Hyg. 2009;80(1):103-11. https://doi.org/10.4269/ajtmh.2009.80.103.

26. National Malaria Control Team, Ethiopian Public Health Institute, World Health Organization, Addis Ababa University and the INFORM Project (2013). An epidemiological profile of malaria in Ethiopia. A report prepared for the Federal Ministry of Health, Eth.

27. Oliveira-Ferreira J, Lacerda MVG, Brasil P, Ladislau JLB, Tauil PL, Daniel-Ribeiro CT. Malaria in Brazil: An overview. Malar J. 2010;9(1):115. https://doi.org/10.11 86/1475-2875-9-115

28. Moshi IR, Manderson L, Ngowo HS, Mlacha YP, Okumu FO, Mnyone LL. Outdoor malaria transmission risks and social life: a qualitative study in south-eastern Tanzania. Malar J. 2018;17(1):397. https://doi.org/10.1186/s12 936-018-2550-8.

29. Robinsona DP, Klein SL. Pregnancy and pregnancy-associated hormones alter immuneresponses and disease pathogenesis. Horm Behav. 2012;62(3): 263-71. https://doi.org/10.1016/j.yhbeh.2012.02.023.

30. Lyon B, Dinku T, Raman A, Thomson MC. Temperature suitability for malaria climbing the Ethiopian highlands. Environ Res Lett. 2017;12(6):064015. https://doi.org/10.1088/1748-9326/aa64e6.

31. Prasad N, Sharples KJ, Murdoch DR, Crump JA. Community prevalence of fever and relationship with malaria among infants and children in lowresource areas. Am J Trop Med Hyg. 2015;93(1):178-80. https://doi.org/10.42 69/ajtmh.14-0646.

32. Okell LC, Bousema T, Griffin JT, Ouédraogo AL, Ghani AC, Drakeley CJ. Factors determining the occurrence of submicroscopic malaria infections and their relevance for control. Nat Commun. 2012;3(1):1237. https://doi. org/10.1038/ncomms2241.

33. Kobayashi T, Kanyangarara M, Laban N, Phiri M, Hamapumbu H, Searle K, et al. Characteristics of subpatent malaria in a pre-elimination setting in southern Zambia. Am J Trop Med Hyg.

34. Baum E, Sattabongkot J, Sirichaisinthop J, Kiattibutr K, Jain A, Taghavian O, et al. Common asymptomatic and submicroscopic malaria infections in Western Thailand revealed in longitudinal molecular and serological studies: a challenge to malaria elimination. Malar J. 2016;15(1):1-15. https://doi.org/1 0.1186/s12936-016-1393-4.

35. Jiram Al, Ooi CH, Rubio JM, Hisam S, Karnan G, Sukor NM, et al. Evidence of asymptomatic submicroscopic malaria in low transmission areas in Belaga district, Kapit division, Sarawak, Malaysia. Malar J. 2019;18(1):156. https://doi. org/10.1186/s12936-019-2786-y.

36. Harris I, Sharrock W, Bain L, Gray KA, Bobogare A, Lilley K, et al. A large proportion of asymptomatic malaria infections with low parasite densities in Temotu Province, Solomon Islands: Challenges for malaria diagnostics in an elimination setting. Malar J. 2010;9(1):254. https://doi.org/10.1186/1475-2 875-9-254.

37. Lin JT, Saunders DL, Meshnick SR. The role of submicroscopic parasitemia in malaria transmission: what is the evidence? Trends Parasitol. 2014;30(4):18390. https://doi.org/10.1016/j.pt.2014.02.004.

38. WHO. world malaria report. Geneva, Swizterland. 2015.

39. Dal-Bianco MP, Köster KB, Kombila UD, Kun JF, Grobusch MP, Ngoma GM, et al. High prevalence of asymptomatic Plasmodium falciparum infection in Gabonese adults. Am J Trop Med Hyg. 77: 939-42.

40. Watson OJ, Sumner KM, Janko M, Goel V, Winskill P, Slater HC, et al. Falsenegative malaria rapid diagnostic test results and their impact on community-based malaria surveys in sub-Saharan Africa. BMJ Glob Heal. 2019;4(4):e001582. https://doi.org/10.1136/bmjgh-2019-001582.

41. Lindblade KA, Steinhardt L, Samuels A, Kachur SP, Slutsker L. The silent threat: asymptomatic parasitemia and malaria transmission. Expert Rev AntiInfect Ther. 2013;11(6):623-39. https://doi.org/10.1586/eri.13.45. 
42. Federal Democratic Republic of Ethiopia, Ministry of Health: Malaria diagnosis and treatment guidelines for health workers in Ethiopia. 2nd edition. Addis Ababa Minist Heal. 2004.

43. World Health Organization (WHO). GUIDELINES FOR THE TREATMENT OF MALARIA. Third edition. 2015. Available: https:/books.google.co.ke/books?hl= en\& $r=\& i d=A m 83 e l 7 \_p o U C \& o i=f n d \& p g=P R 5 \& d q=W H O+$ guidelines+for+the+ treatment+of +malaria+vol+58+2006\&ots=pqWOB1 AR9H\&sig=G56oqYa lyFRyu7dRcGSXH-awEtY\&redir_esc=y\#v=onepage\&q\&f=false

\section{Publisher's Note}

Springer Nature remains neutral with regard to jurisdictional claims in published maps and institutional affiliations.

Ready to submit your research? Choose BMC and benefit from:

- fast, convenient online submission

- thorough peer review by experienced researchers in your field

- rapid publication on acceptance

- support for research data, including large and complex data types

- gold Open Access which fosters wider collaboration and increased citations

- maximum visibility for your research: over $100 \mathrm{M}$ website views per year

At BMC, research is always in progress.

Learn more biomedcentral.com/submissions 